\title{
Farmers' preferences for irrigation water demand management tools: a Bayesian analysis of choice behaviour of farmers in Krishna river basin, India
}

\author{
P. Chellattan Veettil, A. Frija, S. Speelman, J. Buysse \\ \& G. van Huylenbroeck \\ Department of Agricultural Economics, Ghent University, Belgium
}

\begin{abstract}
Policy designers have various water demand management (WDM) strategies to achieve efficient water use and allocation at their disposal, such as setting the price of water, decentralizing irrigation water management or improving the quality of water rights. Interestingly, most of these strategies have been applied individually without focusing on the relations between them. This paper uses a discrete choice model to analyse the scope for and the farmer's acceptance of combinations of irrigation WDM tools. In terms of local irrigation water governance the presence or absence of collective irrigation water management among farmers in the form of water user association (WUA) is considered. Water rights are specified by the duration of the title, by their transferability and by the quality of title. Finally, four types of water pricing methods (area, crop, quota and volumetric pricing) are selected for the experimental design. Using the choice experiment we can elicit the most preferred water pricing method under different water rights, water prices and local irrigation water governance contexts. Our results indicated that under conditions of improved water rights, preference for volumetric pricing increases, while the presence of a WUA decreases this preference. We also showed that making the right combination of WDM tools considerably increases the willingness to pay for a change in scenario.
\end{abstract}

Keywords: complementarity, water pricing method, water rights, local water governance, choice experiment, willingness to pay. 


\section{Introduction}

Ensuring efficient water use and allocation through the introduction of improved irrigation WDM strategies is a prime concern of many developing as well as developed countries. This should help to reduce the escalating irrigation water demand. To tackle the issue, policy designers adopt different strategies such as setting the optimum price for water rights, decentralizing irrigation water management or improving the quality of water rights. Mostly these strategies are adopted individually or when combined, the relation between them is not checked. Farmers, however, live in a micro-environment under a particular type of irrigation water governance and institutional framework with different cropping systems. The linkages between these items are of the utmost importance. In this paper we, therefore, try to analyze the relations between different WDM tools (water pricing methods and the water rights system) in the context of the Krishna river basin in India. These relations are crucial to improving water resource management, particularly water resource allocation and pricing. For example, water pricing in a poor water rights system is often inefficient and will endanger the cost recovery objective, as well as an efficient water allocation. In situations where water rights are improperly defined, transaction costs increase spectacularly, leading to inappropriate valuation of water resources (Speelman et al [1]). According to Liao et al [2], the interactions among different water rights and other attributes are very important determinants of irrigation efficiency. In this light, interactions between WDM tools need to be considered while looking at the efficiency of irrigation pricing methods. Moreover, as several authors have shown ([1], Herrera et al [3]), willingness to pay for water is affected by the institutional context, which enables us to use contingent valuation in the format of choice experiments to study the complementarities. Because participants in a choice experiment (CE) are required to make a deliberation between different attributes of a single profile, responses are usually less strategic. The choice made by a participant in a CE results from valuation of each attribute solely and their interactions. Therefore, to model the influence of the levels of various attributes and their interactions, a $\mathrm{CE}$ is preferred to more conventional contingent valuation methods. To analyse the CE results we use a multinomial probit model (MNP). This model assumes that farmers simultaneously consider all water pricing options while making their choice, which allows us to violate the restrictive substitution pattern (IIA) of the traditionally used multinomial logit model (Train [4]). Using the MNP we can thus assess whether the relative preference of a farmer choosing between two WPMs depends on the presence of other water pricing options.

The remainder of the paper is organized as follows. The second section outlines and briefly discusses the choice experiment setting employed and is followed by a result and discussion section. Finally the paper concludes by highlighting the most important policy implications of the model outcome. 


\section{Discrete choice analysis}

\subsection{Study design}

In order to analyze the complementary relations between water rights, local irrigation water governance and water pricing, we adopted a choice experiment (CE). One of the initial steps in designing a CE is to identify the choice alternatives and their relevant attributes (Hensher et al [5]; Hanley et al [6]). Table 1 provides the attributes for the present choice design. These attributes are identified from literature as well as from focus group discussions. Four WPMs are selected as choice options, which are the area pricing method (APM), crop pricing method (CPM), quota pricing method (QPM) and volumetric pricing method (VPM). In APM (status quo), area pricing is employed, which is based on the total acreage of cropping with no restriction of types of crop cultivation. In CPM the water price varies according to the crops grown. In VPM, the unit price of water is fixed and the price of water is calculated by quantity of water consumed times the unit price of water (single rate volumetric pricing), whereas under the QPM, the price of water varies according to the level of water quota allotted to irrigators.

We developed a generic choice design with a calculated D-efficiency of 0.8326 using SAS macros (see Kuhfield [7] for details). The choice design comprise of 16 choice sets, blocked into 4 groups. Each choice set comprise of 4 alternatives with status quo area pricing. Farmers those who do not wish to opt for any of the proposed alternatives can maintain the status quo position. Each block is administered randomly to 80 respondents. An example of a choice set is shown in table 2 . The base scenario of the experimental design is area pricing

Table 1: $\quad$ Attributes and levels included in the choice sets.

\begin{tabular}{|c|c|c|}
\hline Attribute & Levels & Remarks \\
\hline \multirow[t]{4}{*}{ Transfer } & 1. No transfer & $\begin{array}{l}\text { Water rights cannot be transferred even when the entitled } \\
\text { water is not used by the farmer }\end{array}$ \\
\hline & 2. Within WUA & $\begin{array}{l}\text { Water rights can be transferred partly or fully, temporarily } \\
\text { or permanently to other members within WUA }\end{array}$ \\
\hline & 3. Between WUA & $\begin{array}{l}\text { Water rights are entitled to group (WUA) and transfer of } \\
\text { rights would be possible between WUAs }\end{array}$ \\
\hline & 4. Water market & Water rights can be traded in a water right market \\
\hline \multirow[t]{2}{*}{ Duration } & 1. Short $(<2$ years $)$ & $\begin{array}{l}\text { Water rights entitle to farmers (or WUA) only one or few } \\
\text { crop seasons }\end{array}$ \\
\hline & 2. Long ( $>2$ years) & for longer period so that farmer able to invest on irrigation \\
\hline Supply & $\begin{array}{l}\text { 1. Guaranteed } \\
\text { 2. Not-Guaranteed }\end{array}$ & $\begin{array}{l}\text { When supply is guaranteed, delivery of water is not } \\
\text { interrupted and is according to the contract/title. }\end{array}$ \\
\hline Price & $\begin{array}{l}4 \text { price levels for } \\
\text { each WPM } \\
\text { 1.Price I } \\
\text { 2.Price II } \\
\text { 3.Price III } \\
\text { 4.Price IV }\end{array}$ & $\begin{array}{l}\text { Area pricing: } 150,225,300 \& 400 \mathrm{Rs} / \text { acre } \\
\text { Crop pricing: } 250,350,450,600 \mathrm{Rs} \\
\text { Quota pricing: } 360,600,1260 \& 2100 \mathrm{Rs} \\
\text { (quota levels: } 30,50,70,>70 \text { acre-inch) } \\
\text { Volumetric pricing: } 8,12,18 \& 30 \mathrm{Rs} .{ }^{*} / \text { acre-inch** }\end{array}$ \\
\hline
\end{tabular}

$* 1$ USD $\approx$ Rs.49.46 at the time of investigation; ** 1 acre-inch $=102.790153 \mathrm{~m}^{3}$. 
with a low price level (150Rs./acre) and short duration water rights with no transaction. An improvement from this scenario will result in financial gain through freedom of choice and acreage of crops grown, higher productivity, reduced total payment for water, higher scope of investments for water saving technologies and reduced risk of crop failure due to water shortage. The financial gain of a farmer can be up to 3-5 times for a farmer cultivating sugarcane in the best scenario (volumetric pricing, long duration water rights, water transferability in market and high price) when compared to a farmer cultivating finger millet at the base scenario. Those who cultivate sugarcane under the base scenario under water stress also expect to benefit in the proposed WPM by reduced water stress, risk and increased productivity.

\subsection{Study region and data collection}

The Krishna river basin is one of the major river basins of the delta region of India, nourishing three Southern states: Maharashtra, Karnataka and Andhrapradesh. About $77 \%$ of the total basin area is cultivable $\left(203,000 \mathrm{Km}^{2}\right)$ with an irrigation potential of $47,200 \mathrm{~km}^{2}$. The majority of the basin area is arid or semi arid and faces high water scarcity.

Primary choice data comprising farmers' choices for WPM were collected from the farmers of Krishna river basin area of northern Karnataka state in India from January to March 2008 by face-to-face interviews. This part includes four sub-basins, namely Lower Krishna, Ghataprabha, Malaprabha and Tungabhadra. The villages and farmers within the villages were selected randomly. Data were collected from 320 farmers. The number of villages and farmers selected is proportional to the total number of villages and farmers in the sub-basins. The details of choice experiment settings were explained to the farmers. Each water pricing method and water attributes were explained in detail. The expected benefit and cost for improvement for attribute level from base scenario to other scenario is explained in terms of choice of crop, increased production, risk and investment opportunities.

\subsection{The model}

The CE technique relies on the basic idea that an individual can chose (rationally by maximizing utility) among choice sets comprising different attribute levels.

Table 2: $\quad$ An example choice set.

If options crop price, quota price, volumetric price, area price were only available, which one would you choose?

\begin{tabular}{|c|c|c|c|c|}
\hline Characteristics & Crop price & Quota price & Volumetric price & $\begin{array}{l}\text { Area price } \\
\text { (status quo) }\end{array}$ \\
\hline Duration & Long & Short & Short & Short \\
\hline Supply & Not-guaranteed & Guaranteed & Guaranteed & Not-guaranteed \\
\hline Water transaction & Within WUA & No-Transfer & Between WUA & No-Transfer \\
\hline Payment & $450 \mathrm{Rs}$ & $2100 \mathrm{Rs}$ & 30Rs/acre-inch & $150 \mathrm{Rs}$ \\
\hline I choose & & & & \\
\hline
\end{tabular}


The utility is derived from the characteristics which a good possess rather than from the goods per se. These characteristics or attributes are the source of utility for a consumer and they are produced either individually or by combination of goods. Here respondents are asked to choose between different bundles of goods, which are described in terms of their attributes, or characteristics, and the levels that these take.

Assume that utility depends on choices made from some set $\mathbf{C}$ of alternatives. The representative individual is assumed to have a utility function of the form:

$$
U_{n i}=U\left(Z_{n i}, S_{n}\right)
$$

where, for any individual $n$, a given level of utility will be associated with any alternative water right characteristic $i$. Alternative $I$ will be chosen over some other option $j$ if and only if $U_{i}>U_{j}$. The utility derived from any option is assumed to depend on the attributes, $Z$, of that option. These attributes may be viewed differently by different individuals, whose socioeconomic characteristics $S$ will also affect utility. According to the random utility framework [8], the indirect utility function for each respondent can be partitioned into two parts; one deterministic and in principle observable, and one random and unobservable. Then eqn. (1) can be re-written as:

$$
U_{n i}=V_{n i}+\varepsilon_{n i}
$$

where $V_{n i}=S_{n}^{\prime} \alpha_{i}+Z_{n i}^{\prime} \delta, \alpha$ and $\delta$ are corresponding parameters and the probability that individual $n$ will choose option $i$ over other options $j$ is given by:

$$
\begin{aligned}
& P_{i n}=\operatorname{Pr}\left(V_{i n}+\varepsilon_{i n}>V_{j n}+\varepsilon_{j n}\right) \quad \forall j \neq i \\
& =\operatorname{Pr}\left(\varepsilon_{j n}-\varepsilon_{i n}<V_{i n}-V_{j n}\right) \quad \forall j \neq i \\
& =\int_{\varepsilon} I\left(\varepsilon_{j n}-\varepsilon_{i n}<V_{i n}-V_{j n} \forall j \neq i\right) f\left(\varepsilon_{n}\right) d \varepsilon_{n}
\end{aligned}
$$

where $I($.$) is an indicator function equalling 1$ when the expression in parenthesis is true and 0 otherwise [6]. The probability expression in eqn. (3) is the cumulative distribution of the probability of difference in error $\left(\varepsilon_{j n}-\varepsilon_{i n}\right)$ is below the difference in observed quantity $\left(V_{i n}-V_{j n}\right)$. This give rise to eqn. (4), which is a multidimensional integral over the density of the unobserved portion of utility. The probit model assumes jointly normal error components.

\subsubsection{Bayesian estimation of MNP model}

A farmer's utility for a WPM $i$ is given by eqn. (2) as

$$
\begin{aligned}
U_{n i} & =S_{n}^{\prime} \alpha_{i}+Z_{n i}^{\prime} \delta+\varepsilon_{n i} \\
& i=A P M, C P M, Q P M, V P M
\end{aligned}
$$

we assume that error terms follow a multivariate normal distribution with mean 0 and variance-covariance matrix $\Sigma$, allowing disturbances to be correlated across WPM. In line with random utility models, the farmer chose the WPM which 
gives the farmer highest utility. Following McCulloch et al [8], Imai and van Dyk [9] and Alvarez and Katz [10], we model the observed choice of water pricing method $Y_{i}$ in terms of utility differentials (latent variable)

$$
\begin{gathered}
\widetilde{U}_{k}=U_{k}-U_{A P M}, \quad k=C P M, Q P M, V P M \\
Y_{n}\left(\widetilde{U}_{n}\right)=\left\{\begin{array}{ll}
0 & \text { if } \max \left(\widetilde{U}_{n}\right)<0 \\
j & \text { if } \max \left(\widetilde{U}_{n}\right)=\left(\widetilde{U}_{n j}\right)>0
\end{array} \text { for } n=1, \cdots, N \text { and } j=1, \ldots, k\right.
\end{gathered}
$$

where $Y_{n}=0$ corresponds to the base category APM and $\mathrm{N}$ is the sample size.

$$
\widetilde{U}_{n}=W_{n} \widetilde{\beta}+\widetilde{\varepsilon}_{n}, \quad \text { with } \quad \widetilde{\varepsilon}_{n} \sim N_{3}(0, \widetilde{\Sigma}) \quad \text { and } W_{n}=\left\lfloor S_{n} \otimes I_{3}, Z_{n}^{*}\right\rfloor
$$

$\widetilde{\Sigma}$ is a positive definite $\mathrm{k} \times \mathrm{k}$ matrix with first diagonal element is fixed $\left(\widetilde{\sigma}_{11}=1\right)$ for identification purpose of model parameters $\theta=(\widetilde{\beta}, \widetilde{\Sigma})$ in MNP. The likelihood for the multinomial probit model is given by,

$$
\begin{aligned}
& L(Y \mid W, \theta)=\prod_{n=1}^{N} \operatorname{Pr}\left(Y_{n} \mid W, \theta\right) \\
& P\left(Y_{n} \mid W, \theta\right)=\int_{Y_{n}\left(\widetilde{U}_{n}\right)} \phi_{3}\left(\widetilde{U}_{n} \mid W_{n}, \widetilde{\beta}, \widetilde{\Sigma}\right) d \widetilde{U}_{n}
\end{aligned}
$$

where $\phi_{3}$ is a trivariate normal probability density function.

Bayesian estimation of MNP model was done through Markov chain Monte Carlo simulations using Gibbs sampling algorithm proposed by McCulloch and Rossi (McCulloch et al [8], Imai and van Dyk [9], McCulloch and Rossi [11]). This procedure allow us to use the finite sample inferences instead of large sample theory for which a large sample size is required for accurate asymptotic approximations for discrete dependent variables $[10,11]$. The prior distribution for the model parameters are:

$$
\widetilde{\beta} \mid \widetilde{\Sigma} \sim N\left(\beta_{0}, B^{-1}\right) \text { and } \tilde{\Sigma} \sim \operatorname{inv} \operatorname{Wishart}(v, \widetilde{\Delta})
$$

where $\beta_{0}(=0)$ and $\mathrm{B}^{-1}(=0.0001 I)$ are the prior mean and variance of $\beta, v(=6)$ is the degrees of freedom for $\Sigma$ and $\Delta(=v I)$ is the matrix for prior scale of $\Sigma$ [8]. The joint posterior distribution of the parameters is given by Bayes theorem as

$$
k(\widetilde{\beta}, \widetilde{\Sigma} \mid W) \propto L(Y \mid W, \widetilde{\beta}, \widetilde{\Sigma}) \pi(\widetilde{\beta}) \pi(\widetilde{\Sigma})
$$

The details of the data augmentation algorithm are presented in [9]. The sample obtained after suitable burn in period (where convergence occurred) is regarded as the sample from the target posterior distribution [9]. For estimation, we assume diffuse proper priors for the parameters in the model. Routine sensitivity analyses were done with respect to different priors and starting values, yielding similar results. Convergence of MCMC is diagnosed using Gelman-Rubin [12] statistic. A single Markov chain was run for 1,000,000 cycles, with the first 500,000 were discarded as burn in and a thinning interval of 10 is used. The results presented in section are based on the above 50,000 Gibbs draws of the parameters. The estimation is done using $\mathrm{R}$ package Bayesm. 


\subsubsection{Willingness-to-pay (WTP)}

WTP estimates are derived by determining the price differences necessary to invoke differences between two attributes or attribute levels (Lusk and Schroeder [13]). Total WTP to obtain water pricing method $j$ versus area pricing is calculated as the ratio of the alternative specific constant to the price coefficient $\left(-\beta_{j} / \alpha_{j}\right)$. Following [13], marginal WTP for water pricing $j$ versus $k$ can be calculated by subtracting total WTP for water pricing $j$ from total WTP for water pricing $k\left(-\beta_{j} / \alpha_{j}+\beta_{k} / \alpha_{k}\right)$.

\section{Empirical results}

\subsection{Multinomial probit estimates}

Table 3 reports the posterior mean and 95\% Bayesian credible intervals of the parameters of multinomial probit model. The summaries of posterior densities explicitly point out the relative influence of water attributes and socio demographic variables in the choice of water pricing method. The parameter estimates denote the marginal utility associated with a change from the attribute levels of existing APM. The size of irrigated land significantly influences the choice of quota and volumetric pricing methods. Larger farmers in terms of amount of irrigated land, are more likely to choose quota and volumetric than area pricing method at $95 \%$ and $90 \%$ level, respectively. However, the size of farm measured as amount of irrigated land does not influence significantly the choice between crop and area pricing method. The dummy variable price-high captures the adverse effect of high level of price on choice probability of water pricing method (Alfnes et al [14]). A high level of price positively influences the choice of CPM and VPM compared to APM whereas this high level of price negatively and significantly influence the choice between QPM and APM. The insignificance of the coefficient of the price-high dummy of VPM explains that the choice of farmers between APM and VPM is not adversely influenced by the high level of price. That is, the stated preference for VPM in the model explains the actual preference of farmers. According to many researchers irrigation water demand is inelastic below a threshold price level, and elastic beyond it (VarelaOrtega et al [15]). Volumetric pricing can capture this price elasticity at higher irrigation price level which is explicitly exhibited by the high choice probability for such WPM in our study. Farmers in the presence of WUA are more likely to opt for APM than CPM or QPM or VPM. Interestingly, all the socio-economic variables are significantly affecting the choice of water pricing method. Among the choice specific variables, the duration of water rights and guarantee of supply are not significantly influencing the choice of WPM. All the three levels of water transaction are significantly and positively influencing the choice of WPM compared to No water transaction.

The parameter estimate of price showed that the marginal utility associated with an increase of price by one unit cause a decrease of utility by 1.73 unit. The effect of price on probability of choosing WPM is negative and significant which 
34 Sustainable Irrigation Management, Technologies and Policies III

Table 3: $\quad$ Parameter estimation of MNP choice model.

\begin{tabular}{|c|c|c|c|}
\hline Coefficients & mean & Std error & $\begin{array}{l}{[95 \% \text { Bayesian }} \\
\text { credible interval }]\end{array}$ \\
\hline \multicolumn{4}{|l|}{ Intercept } \\
\hline Crop/Area & $-1.364^{* *}$ & 0.828 & {$[-3.3666,-0.128]$} \\
\hline Quota/Area & $2.142^{* *}$ & 0.969 & {$[0.6418,4.486]$} \\
\hline Volumetric/Area & 0.277 & 0.775 & {$[-1.4927,1.695]$} \\
\hline \multicolumn{4}{|l|}{ Transaction } \\
\hline Within WUA & $1.214^{*}$ & 0.83 & {$[-0.0176,3.193]$} \\
\hline Between WUA & $2.315^{* *}$ & 1.406 & {$[0.2917,5.749]$} \\
\hline Water market & $1.325^{* *}$ & 0.834 & {$[0.0458,3.289]$} \\
\hline Duration & 0.292 & 0.352 & {$[-0.252,1.140]$} \\
\hline Supply & -0.306 & 0.372 & {$[-1.040,0.465]$} \\
\hline Price & $-1.735^{* *}$ & 0.813 & {$[-3.741,-0.445]$} \\
\hline \multicolumn{4}{|l|}{ WUA (dummy) } \\
\hline Crop/Area & $-0.541^{*}$ & 0.29 & {$[-1.086,0.053]$} \\
\hline Quota/Area & $-2.881^{* *}$ & 1.393 & {$[-6.289,-0.758]$} \\
\hline Volumetric/Area & $-1.752^{* *}$ & 0.982 & {$[-4.161,-0.339]$} \\
\hline \multicolumn{4}{|l|}{ Price-high (dummy) } \\
\hline Crop/Area & $0.545^{*}$ & 0.291 & {$[-0.013,1.125]$} \\
\hline Quota/Area & $-2.164^{* *}$ & 1.28 & {$[-5.245,-0.335]$} \\
\hline Volumetric/Area & 0.563 & 0.707 & {$[-0.582,2.213]$} \\
\hline \multicolumn{4}{|l|}{ Irrigated land } \\
\hline Crop/Area & 0.018 & 0.022 & {$[-0.026,0.063]$} \\
\hline Quota/Area & $0.071^{* *}$ & 0.051 & {$[0.0069,0.198]$} \\
\hline Volumetric/Area & $0.055^{*}$ & 0.046 & {$[-0.0051,0.168]$} \\
\hline \multicolumn{4}{|l|}{ Variance - Covariance } \\
\hline Crop/Area: Crop/Area & 1 & 0 & \\
\hline Crop/Area: Quota/Area & 0.4486 & 1.2353 & {$[-2.4476,2.7957]$} \\
\hline Crop/Area: Volumetric/Area & 1.1596 & 1.1196 & {$[-1.1887,3.4032]$} \\
\hline Quota/Area: Quota/Area & $6.1917^{* *}$ & 6.9917 & {$[0.3112,24.9739]$} \\
\hline Quota/Area: Volumetric/Area & $5.4101^{* *}$ & 6.0933 & {$[0.2004,21.2792]$} \\
\hline Volumetric/Area: Volumetric/Area & $6.2221^{* *}$ & 7.0012 & {$[0.2194,23.7224]$} \\
\hline
\end{tabular}

" and ${ }^{* *}$, significant at $90 \%$ and $95 \%$ level of Bayesian credible interval.

is in conformity with standard economic theories. The estimates of covariance structure is difficult to explain directly as it replicates the covariance structure of error differences. Hence we rely on substitution pattern of WPM in two conditions: the current situation and an increase of price of area by $25 \%$. If there is no covariance structure exists, the pattern of substitution follow IIA, but Table 4 clearly shows violation of IIA.

There exists a covariance structure in the choice preferences of WPM which makes a difference in percentage shift for different alternatives [6]. When the price of water goes up by $25 \%$, the number of farmers opting for VPM would 
Table 4: $\quad$ Substitution pattern of MNP choice model with $25 \%$ increase in price.

\begin{tabular}{ccccc}
\hline WPM & $\begin{array}{c}\text { Present } \\
\text { condition }\end{array}$ & $\begin{array}{c}25 \% \text { increase in } \\
\text { price }\end{array}$ & $\begin{array}{c}\text { Difference in } \\
\text { probability }(\%)\end{array}$ & $\begin{array}{c}\text { \% Change (from } \\
\text { current scenario) }\end{array}$ \\
\hline Area & 0.1938 & 0.1723 & -2.15 & -11.09 \\
Crop & 0.2406 & 0.2249 & -1.57 & -6.53 \\
Quota & 0.2085 & 0.1965 & -1.2 & -5.76 \\
Volumetric & 0.3570 & 0.4062 & +4.92 & +13.78 \\
\hline
\end{tabular}

Table 5: $\quad$ Marginal WTP estimates for complementary relations.

\begin{tabular}{cccc}
\hline Water pricing $^{\text {a }}$ & $\begin{array}{c}\text { Local water } \\
\text { Governance }^{\text {a }}\end{array}$ & Water rights a & $\begin{array}{c}\text { WTP } \\
\text { (Rs./ acre-inch) }\end{array}$ \\
\hline Volumetric pricing & Absent & Poorly defined & 3.19 \\
Volumetric pricing & Present & Poorly defined & -17.00 \\
Volumetric pricing & Absent & Well defined & 18.47 \\
Volumetric pricing & Present & Well defined & -1.73 \\
\hline
\end{tabular}

( ${ }^{a}$ Base level: Area pricing with the absence of local water governance and poorly defined water rights)

increase by $14 \%$ whereas the all other WPM would decrease. The shifts from CPM and QPM to VPM (6.5 and 5.7\% respectively) are nearly equal, whereas it is $11 \%$ for APM to VPM (Table 4). This shows an increased acceptance of VPM at higher price levels. It is clear from the substitution pattern that farmers prefer a shift to VPM rather than to CPM or QPM or APM.

\subsection{WTP for interactions between WDM tools in VPM}

The WTP for interactions between WDM tools are calculated and reported in Table 5. These WTP estimates are in comparison to the base scenario with area pricing, absence of WUA and poorly defined water rights. In all types of relations between pricing, local governance and water rights, the presence of WUA causes a decline in WTP (-17 and -1.73 Rs./acre-inch in case of poorly defined and well defined water rights respectively) when compared to that of similar scenario without the presence of WUA. Thus we conclude that there is a conflicting relation between water governance and pricing as well as between water governance and water rights. The positive relation is evident between water pricing and water rights where as the conflicting relation of presence of WUA reduce the WTP. Ahmad [16] argues that in the absence of well defined water right systems, pricing of water may lead to higher water use instead of reducing it. Additionally, the study of alternative ground water pricing policies in water scarce regions of India by Shiferaw et al [17] stressed the importance of local institutions in implementing alternative water pricing policies. They reported a higher acceptance of volumetric pricing based on local experiences such as irrigation charges for a predictable flow per hour. Tsur [18] has mentioned that volumetric based irrigation charges were mainly limited to developed countries due to poor infrastructure facilities available in developing countries. High complementary relations are evident between volumetric pricing 
and water rights (Rs. 18/acre-inch) when there is no WUA. Thus improvement of water governance structure is necessary to effectively taper complementary relations between water pricing and water rights. World Bank [19] has also reported the difficulties of collecting water payment and has suggested to introduce water rights as well as to set up of local water governance institutions. However, our study demonstrates that presence of such local water institutions can obstruct the efficiency of improved WPM such as VPM.

\section{Final remarks}

Improved, efficient water pricing is a prime requisite of the rapid growing irrigation sector in India. The introduction of pricing or tax policy for a scarce water resource demands a multidimensional search taking account of different water and allied sectors, stakeholders, socio-demographic, political and geophysical conditions etc. The ideal situation of efficient use of a resource is that proper quantification and administration of the price which is directly applied per unit of undesirable output or limited resource. Therefore, irrigation water pricing involving any kind of volumetric measurement should be the preferred choice. However, transaction cost should not be ignored because they can play an important role in the organization and the control of a pricing system. The present study uses the farmers' perspective to balance between high environmental and economic efficiency and low transactions costs. The result of the study can give ex ante advice about the optimal water pricing and its complementary association with water rights and governance. It is important for farmers to pay only for the water they have actually used especially at high water tariff structure. This can be achieved by volumetric water pricing. The transaction cost depends on water governance as well as water rights and other water institutions. In the current water scarce situation, volumetric pricing is expected to give the best incentive for farmers to increase water use efficiency (Molle and Berkoff [20]).

The cost recovery, efficiency and WDM can be achieved with lower unit price by volumetric based pricing methods. When such pricing method with carefully designed institutional structure is introduced, farmers adopt more efficient and water saving techniques [20]. The WTP estimation showed that volumetric pricing with well defined water rights and improved management of local water governance provide the best result from farmers' perspective. Hence, the focus of the policy should be for VPM with improved water rights and water management. The option of VPM depends on the geophysical and socioeconomic situations in the region and other administrative issues such as decentralisation of water governance, water rights allocation, equity, water availability/supply etc.

\section{References}

[1] Speelman, S., D’Haese, M., Frija, A., Farolfi, S. \& D’Haese, L. Willingness to pay for water and water rights definition: Study among smallholder 
irrigators in Limpopo province, South-Africa. Proc. of $V^{\text {th }}$ Int. Conf. On Sustainable Water Resources Management, C.A. Brebbia \& V. Popov WIT, Southampton, U.K. pp. 341-352, 2009.

[2] Liao, Y., Giordano, M. \& Fraiture, C. An empirical analysis of the impacts of irrigation pricing reforms in China. Water Policy, 9, pp. 45-60, 2007.

[3] Herrera, P., Huylenbroeck, G. \& Espinel. R. An introduction of the contingent valuation method to assess the efficiency of the institutional structure of irrigation property rights: The case of the peninsula of Santa Elena. Int. J. of Water Resource Development, 20 (4), pp. 537-551, 2004.

[4] Train, K. Discrete Choice Methods with Simulation, Cambridge University Press, Cambridge, 2003.

[5] Hensher, D. A., Rose, J. M. \& Greene, W. H. Applied Choice Analysis: A Primer. Cambridge University Press, Cambridge, 2005.

[6] Hanley, N., Mourato, S. \& Wright, R. E. Choice Modelling Approaches: A Superior Alternative for Environmental Valuation?. J. of Economic Surveys, 15(3), pp. 435-462, 2001.

[7] Kuhfeld, W. F. Marketing Research Methods in SAS Online http://support.sas.com/techsup/technote/ts722title.pdf.

[8] McCulloch, R. E., N. G. Polson, et al. A Bayesian analysis of the multinomial probit model with fully identified parameters. $J$. of Econometrics, 99(1), pp. 173-193, 2000.

[9] Imai, K. \& van Dyk D. A. A Bayesian analysis of the multinomial probit model using marginal data augmentation. J. of Econometrics, 124(2), pp. 311-334, 2005.

[10] Alvarez, R. M. \& Katz, G. Structural cleavages, electoral competition and partisan divide: A Bayesian multinomial probit analysis of Chile's 2005 election. Electoral Studies, 28(2), pp. 177-189, 2009.

[11] McCulloch, R. \& Rossi, P.E. An exact likelihood analysis of the multinomial probit model, J. of Econometrics, 99, pp. 173-193, 1994.

[12] Gelman, A. \& Rubin, D. B. Inference from Iterative Simulations Using Multiple Sequences. Statistical Science, 7, pp. 457-472, 1992.

[13] Lusk, J. L. \& Schroeder, T. C. Are Choice Experiments Incentive Compatible? A Test with Quality Differentiated Beef Steaks. A. J. Agri. Econ. 86(2), pp. 467-482, 2004.

[14] Alfnes, F., Guttormsen, A. G., Steine, G. \& Kolstad, K. Consumers' Willingness to Pay for the Color of Salmon: A Choice Experiment with Real Economic Incentives. American. J. Agri. Econ., 88(4), 1050-1061, 2006.

[15] Varela-Ortega, C., Sumpi, J.M., Garrido, A., Blanco, M. \& Iglesias, E. Water pricing policies, public decision making and farmers' response: implication for water policy. Agricultural Economics, 19, pp. 193-202, 1998.

[16] Ahmad, M. Water pricing and markets in the Near East: Policy issues and options. Water Policy 2, pp. 229-242, 2000.

[17] Shiferaw, B., Reddy, V. R. \& Wani, S. P. Watershed externalities, shifting cropping patterns and groundwater depletion in Indian semi-arid villages: 
38 Sustainable Irrigation Management, Technologies and Policies III

The effect of alternative water pricing policies. Ecological Economics, 67(2), 327-340, 2008.

[18] Tsur, Y. Economic aspects of irrigation water pricing. Canadian Water Resource Journal, 30(1), pp. 31-46, 2005.

[19] World Bank. World Bank Water Resources Sector Strategy: Strategic Directions for World Bank Engagement. World Bank, Washington, DC., 2003.

[20] Molle, F. \& Berkoff, J. Water Pricing in Irrigation: Mapping the Debate in the Light of Experience. Irrigation water pricing: The gap between theory and practice, eds. F. Molle \& J. Berkoff, CAB International, UK., 2007. 